\title{
Targeting working memory to modify emotional reactivity in adult attention deficit hyperactivity disorder: a functional magnetic resonance imaging study
}

\author{
Antonia Kaiser ${ }^{1}$ D $\cdot$ Liesbeth Reneman ${ }^{1} \cdot$ Paul J. Lucassen $^{2} \cdot$ Taco J. de Vries $^{3} \cdot$ Anouk Schrantee $^{1}$. \\ Anne Marije Kaag ${ }^{4,5,6}$
}

Accepted: 31 July 2021 / Published online: 15 September 2021

(c) The Author(s) 2021

\begin{abstract}
Understanding the neural mechanisms of emotional reactivity in Attention-Deficit/Hyperactivity Disorder (ADHD) may help develop more effective treatments that target emotion dysregulation. In adult ADHD, emotion regulation problems cover a range of dimensions, including emotional reactivity (ER). One important process that could underlie an impaired ER in ADHD might be impaired working memory (WM) processing. We recently demonstrated that taxing WM prior to the exposure of emotionally salient stimuli reduced physiological and subjective reactivity to such cues in heavy drinkers, suggesting lasting effects of WM activation on ER. Here, we investigated neural mechanisms that could underlie the interaction between WM and ER in adult ADHD participants. We included 30 male ADHD participants and 30 matched controls. Participants performed a novel functional magnetic resonance imaging paradigm in which active WM-blocks were alternated with passive blocks of negative and neutral images. We demonstrated group-independent significant main effects of negative emotional images on amygdala activation, and WM-load on paracingulate gyrus and dorsolateral prefrontal cortex activation. Contrary to earlier reports in adolescent ADHD, no impairments were found in neural correlates of WM or ER. Moreover, taxing WM did not alter the neural correlates of ER in either ADHD or control participants. While we did find effects on the amygdala, paCG, and dlPFC activation, we did not find interactions between WM and ER, possibly due to the relatively unimpaired ADHD population and a well-matched control group. Whether targeting WM might be effective in participants with ADHD with severe ER impairments remains to be investigated.
\end{abstract}

Keywords Adult Attention-Deficit/Hyperactivity Disorder (ADHD) · Emotional dysregulation · Emotional reactivity · Functional magnetic resonance imaging (fMRI) · Working memory

Anouk Schrantee and Anne Marije Kaag have contributed equally.

Antonia Kaiser

a.kaiser@amsterdamumc.nl

1 Department of Radiology and Nuclear Medicine, Amsterdam UMC, University of Amsterdam, Amsterdam Neuroscience, Location AMC, Meibergdreef 9, 1105AZ Amsterdam, The Netherlands

2 Brain Plasticity Group, Swammerdam Institute for Life Sciences, Center for Neuroscience, University of Amsterdam, Amsterdam Neuroscience, Amsterdam, The Netherlands

3 Department of Anatomy and Neurosciences, Amsterdam UMC, Vrije Universiteit Amsterdam, Amsterdam Neuroscience, Amsterdam, The Netherlands
4 Department of Psychiatry, Amsterdam UMC, University of Amsterdam, Amsterdam Neuroscience, Amsterdam, The Netherlands

5 Department of Developmental Psychology, University of Amsterdam, Amsterdam Neuroscience, Amsterdam, The Netherlands

6 Neuro- and Developmental Psychology, Department of Clinical Neuropsychology, Vrije Universiteit Amsterdam, Amsterdam Neuroscience, Amsterdam, The Netherlands 


\section{Introduction}

In addition to deficits in attention, hyperactivity, and impulsivity (American Psychiatric Association, 2000), emotional dysregulation (ED) is considered a core symptom in adults with Attention-Deficit/Hyperactivity Disorder (ADHD) (Hirsch et al., 2019). ED is defined as the inability to control and minimize the disrupting effects of irrelevant emotional stimuli on goal-oriented processes (Barkley \& Fischer, 2010; Wehmeier et al., 2010). In adult ADHD, problems with emotion regulation include emotional recognition, emotional responsivity, and emotional lability, adding to the complexity of the spectrum of classic symptoms (Beheshti et al., 2020). Importantly, ED predicts lower quality of life in young adults (Groenewold et al., 2013) and is associated with the persistence of ADHD into adulthood (Barkley \& Fischer, 2010). A recent meta-analysis demonstrated that pharmacological treatments have limited efficacy for ED in adults (Lenzi et al., 2018), yielding therapeutic challenges. As such, better insights into underlying (neural) mechanisms of ED in adult ADHD could help develop more effective treatments.

A critical aspect of ED in ADHD is impaired emotional reactivity (ER): the threshold, intensity, or duration of affective arousal, which can be measured through the processing of emotionally salient stimuli (Graziano \& Garcia, 2015). Adult participants with ADHD do not appear to have deficits in the explicit regulation of emotions, but display emotional hyper-responsivity (Materna et al., 2019). For example, higher emotional lability has been associated with a hyper-connectivity of the corticoamygdalar network, including the anterior cingulate cortex, both in children and adolescents (Hulvershorn et al., 2014; Hafeman et al., 2017). In children with ADHD, the processing of negative emotional faces stimuli has been associated with amygdala hyper-connectivity and hyperreactivity (Brotman et al., 2010; Posner et al., 2011a, 2011b; Quinlan et al., 2017); and was notably also linked to ED (Herrmann et al., 2010). In adults with ADHD, amygdala hyperactivity has further been demonstrated in response to salient stimuli (Maier et al., 2014; Plichta et al., 2009; Tajima-Pozo et al., 2018), but divergent findings have been reported as well (Hägele et al., 2016; Tajima-Pozo et al., 2015) and the exact neural mechanisms that underlie ER in adult ADHD thus remain still unclear.

Emotional regulation has been shown to be influenced by top-down cognitive control processes. For example, in controls, the prefrontal cortex (PFC) was activated stronger in the presence of emotional stimuli during cognitive control tasks (Hung et al., 2018; Song et al., 2017) and cognitively demanding tasks could tune down amygdala reactivity to emotional stimuli, suggesting top-down suppression of ER (Erk et al., 2007; Van Dillen et al., 2009). Furthermore, taxing WM during or prior to the exposure of emotionally salient stimuli reduced ER in both anxiety and substance use disorders (Andrade et al., 2012; Kaag et al., 2018; Markus et al., 2016; May et al., 2010; McClelland et al., 2006; van den Hout et al., 2014). Additionally, WM training has been shown to improve ER outcomes in healthy individuals as well as in individuals with psychiatric disorders other than ADHD (Barkus, 2020; Schweizer et al., 2013). Whether this affects (the neural mechanisms underlying) emotional processing remains to be determined. Indeed, an underdeveloped working memory (WM) system may underlie impaired ER in ADHD (Groves et al., 2020). More specifically, ADHD participants perform worse (Marx et al., 2011) and show reduced WM-related PFC activation in WM-tasks (Cortese et al., 2012; Burgess et al., 2010; Ko et al., 2013). Altogether, this indicates that while WM and ER are strongly related, the underlying neural mechanisms of how emotional and WM processes interact in ADHD are still unclear (Tsai et al., 20202020).

Therefore, this study aims to test whether targeting WM processes can reduce ER-related neural activity in adult ADHD, through top-down PFC suppression of amygdala hyperactivity. In order to disentangle neural mechanisms of emotional and WM processes, we used a novel functional magnetic resonance imaging (fMRI) paradigm, interleaving emotional stimuli with WM-load blocks. We expected that ADHD participants, compared to controls, would show higher levels of amygdala activation in response to negative emotional, relative to neutral images. Moreover, participants with ADHD were expected to show decreased dorsolateral PFC (dlPFC) and paracingulate gyrus (paCG) responses to high versus low WM-load tasks. We furthermore expected amygdala reactivity in participants with ADHD to be reduced in response to negative emotional blocks following high WM-load more so than in controls.

\section{Methods and materials}

\section{Participants}

Thirty adults with ADHD and 30 controls (19-35 years of age) were included in the study. Inclusion criterion for the ADHD group was prior clinical ADHD diagnosis according to the DSM-IV (American Psychiatric Association, 2000); controls were excluded with a score $>4$ on the ADHD Rating Scale (ADHD-RS) (Kooij et al., 2008). Controls were matched to the participants with ADHD, based on age, 
educational-level, tobacco use (Fagerström Test for Nicotine Dependence)(Heatherton et al., 1991), alcohol use [Alcohol Use Disorders Identification Test (AUDIT)] (Saunders et al., 1993), cannabis use [Cannabis Use Disorders Identification Test (CUDIT)] (Adamson \& Sellman, 2003), and the use of additional substances [Drug Use Disorders Identification Test (DUDIT)] (Berman et al., 2005). Medicated participants with ADHD $(\mathrm{N}=12)$ were instructed to refrain from ADHD medication use for seven days before the MRI scan. Exclusion criteria were: history of brain trauma, neurological disease, excessive consumption of alcohol (AUDIT $>12$ ), cannabis (CUDIT $>12$ ) or other drugs (DUDIT $>12$ ), and MRI contra-indications. For control participants: psychiatric disorders for which they had ever received treatment; for participants with ADHD: psychiatric disorders other than ADHD for which they received treatment at the moment of the experiment. Anxiety, depression, and impulsivity were assessed using the State and Trait Anxiety Inventory (STAI) (Marteau \& Bekker, 1992), Beck's Depression Inventory (BDI) (Beck et al., 1961), and Barratt's Impulsiveness scale (BIS) (Patton et al., 1995), respectively. Written informed consent was obtained from all participants. The study was approved by the Ethics Review Board of the University of Amsterdam.

\section{Statistical analyses}

Data points more than three standard deviations from the mean were removed as outliers (results before and after outlier removal did not differ). Analyses of task and fMRI data used linear mixed-effects models (lme4 Rv.3.5.3) (Bates et al., 2014; R Development Core Team, 2011). In the case of non-normal distributions, transformations were applied. The main and interaction effects of emotional load, WMload, and group were assessed as fixed effects. We used an adjusted top-down model selection process using the Bayesian information criterion (BIC) for model comparison
(Fabozzi et al., 2014; Schwarz, 1978). The model best capturing the data was reported and compared using $\chi^{2}$ tests and BICs. $\mathrm{P}<0.05$ was considered statistically significant (Supplementary Materials 1.5).

\section{MRI acquisition}

Participants were scanned on a $3 \mathrm{~T}$ whole-body MR system (Philips, Best, The Netherlands) using a 32-channel receive-only head-coil. T1-weighted (T1w) scans were obtained using a 3D-TFE sequence (resolution $=0.8 \mathrm{~mm}^{3}$, $\mathrm{FOV}=240 \times 256 \times 200 \mathrm{~mm}, \mathrm{TR} / \mathrm{TE}=9.8 \mathrm{~ms} / 4.5 \mathrm{~ms}$ ). Functional scans were acquired using a 2D-GE-EPI sequence (resolution $=2.5 \times 2.5 \times 2.2 \mathrm{~mm}, \mathrm{FOV}=240 \times 240 \times 131.8 \mathrm{~mm}$, $\mathrm{TR} / \mathrm{TE}=1500 \mathrm{~ms} / 30 \mathrm{~ms}, \mathrm{FA}=70^{\circ}, \mathrm{MB}$-factor $=3$, SENSE $=1.5$ ). A scan with opposite phase-encoding-direction was used for distortion correction.

\section{fMRI paradigm}

The experimental fMRI paradigm (Fig. 1) comprised a blocked design wherein active blocks with either the zeroback or the two-back task ('WM-block') were interleaved with passive blocks consisting of either emotionally neutral or emotionally negative pictures ('EMO-block'). This resulted in four conditions: two-back followed by negative pictures (2E), two-back followed by neutral pictures $(2 \mathrm{~N})$, zero-back followed by negative pictures $(0 \mathrm{E})$, and zeroback followed by neutral pictures $(0 \mathrm{~N})$. The order of the blocks was randomized per participant, under the conditions that 1) the experiment started with a WM-block and 2) blocks were never immediately followed by the same type.

The WM-blocks consisted of a standard 0-back and 2-back task (Cousijn et al., 2014; Supplementary Methods 1.2). During the emotional block, 64 pictures from the International Affective Picture System (IAPS; Supplementary

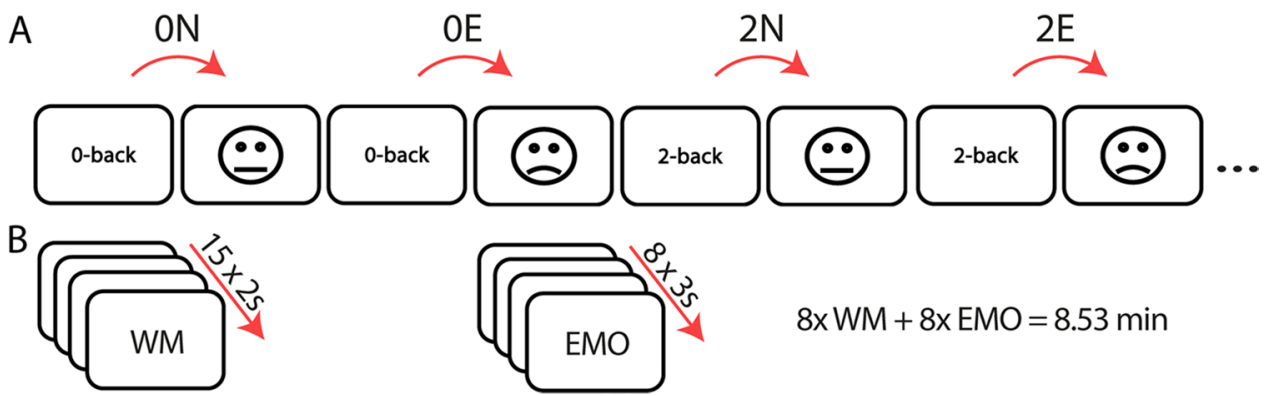

Fig. 1 Study design: A) Interleaved active n-back blocks and passive emotional stimuli blocks. The effect of WM-blocks preceding emotional stimuli was assessed by subdividing the emotional stimuli into four conditions: neutral-after-0-back $(0 \mathrm{~N})$, emotional-after-0-back $(0 \mathrm{E})$, neutral-after-2-back ( $2 \mathrm{~N})$, emotional-after-2-back (2E). B) The working memory (WM) blocks consisted of 15 trials lasting $2 \mathrm{~s}$ each. The emotional images blocks (EMO) consisted of 8 trials lasting $3 \mathrm{~s}$ each. Every condition was shown twice, resulting in $8 \mathrm{WM}$ and 8 EMO-blocks randomly interleaved, which results in a total task duration of 8:53 min 
Materials 1.2) were shown (32 emotionally negative and 32 emotionally neutral; Fig. 1) (Lang et al., 2005). The percentage of correct responses in the n-back task were compared between conditions and groups. All participants performed a recognition task after the fMRI experiment to determine whether both groups paid equal attention to the images during the fMRI-task. Subsequently, participants performed a validation task, in which they rated the valence of all images using the Self-Assessment Manikin (SAM) rating from one ('negative') to nine ('positive') (Lang, 1980) (Supplementary Materials 1.2-1.3).

\section{fMRI processing}

Preprocessing was performed using FMRIPREP v1.2.3 (Esteban et al., 2019, 2020) [RRID: SCR_016216]. Each T1w scan was normalized to MNI space. Functional data preprocessing included motion correction (FLIRT), distortion correction (3dQwarp), followed by co-registration to the $\mathrm{T} 1 \mathrm{w}$. Independent component analysis (ICA) based Automatic Removal Of Motion Artifacts (AROMA) was used to generate data that was non-aggressively denoised. Subsequently, data were spatially smoothed (6mm FWHM) and high pass-filtered (342s) using FSL (Supplementary Methods 1.5).

FMRI data were entered into the first-level analysis (FSL/ FEAT v.6.00; RRID: SCR_002823) (Jenkinson et al., 2012). The model was designed to estimate the effect of WM-load on the neural correlates of emotional processing (Supplementary Materials 1.5). To explore whole-brain activity in the main task contrasts (two-back vs. zero-back; emotional vs. neutral), the first-level contrast-of-parameter-estimates (COPE) maps were analyzed using non-parametric permutation testing (5000 permutations), using FSL Randomise. Thresholds for all analyses were initially set at $\mathrm{p}<0.05$ with family-wise error corrections using threshold-free cluster enhancement (Winkler et al., 2014). Mean framewise displacement per participant was added as a confound regressor.

ROI) analyses used predefined ROIs: Amygdala, dlPFC, and paCG (Supplementary Methods 1.4). The amygdala is a key region in emotional processing (Sergerie et al., 2008), the dIPFC and paCG play an important role in executive functioning, especially during WM-back tasks (MiróPadilla et al., 2018), whereas the paCG shows overlapping activation during negative affect and cognitive control paradigms (Lin et al., 2015; Shackman et al., 2011). Hemisphere differences were tested using paired t-tests and found to be significant for the dIPFC, but not the amygdala. The left and right dIPFC were therefore analyzed separately, whereas parameters were averaged across hemispheres for the amygdala. Featquery (FSL) was used to extract the COPEs, which were converted to percentage change.

\section{Results}

\section{Participants}

Participants with ADHD and controls were well-matched (Table 1). Two participants were removed from the analysis, due to extreme motion during the fMRI-task (framewise displacement $>1.5 * 95 \% \mathrm{CI}$ ).

\section{Behavioral measures}

We found no interaction between WM-load and group on n-back accuracy $\left(\chi^{2}(1)=1.68, p=0.19, \Delta \mathrm{BIC}=-3.07\right)$, but a main effect of WM-load was found $\left(\chi^{2}(1)=40.29\right.$, $\mathrm{p}<0.001, \Delta \mathrm{BIC}=34.87$ ) (Fig. 2A). The d-prime of the recognition task suggests that more attention was paid towards negative emotional images $\left(\chi^{2}(1)=6.78, p<0.01\right.$, $\triangle \mathrm{BIC}=1.36)$, and that attention reduced after high-load WM-blocks $\left(\chi^{2}(1)=34.87, \mathrm{p}<0.001, \Delta \mathrm{BIC}=1.36\right)$ (Fig. 2B). Additionally, we found a trend towards an interaction effect of group and emotional image type $\left(\chi^{2}(1)=3.68\right.$, $\mathrm{p}=0.05, \Delta \mathrm{BIC}=-1.74)$, suggesting that participants with ADHD paid more attention to the negative emotional images compared to controls. The validation task showed that negative images were perceived as more negative than the neutral images by both groups $\left(\chi^{2}(1)=143.29, \mathrm{p}<0.001\right.$, $\Delta \mathrm{BIC}=138.55)($ Fig. 2C).

\section{fMRI}

Exploratory whole-brain analysis assessed the effects of WM-load, emotional image type, and group. Permutation tests revealed the expected main effects of the WM-load and a main effect of the emotional image type in the executive and salience network, respectively (Fig. 3, Supplementary Results 2.2). In contrast to our hypothesis, we found no main effect of group nor any two- or three-way interactions of WM-load, emotional image type, and group.

In line with the whole brain results, we found no significant interaction between WM-load and group on PaCG activation and left dlPFC (PaCG: $\chi^{2}(1)=2.01, \mathrm{p}=0.15$, $\triangle \mathrm{BIC}=-2.73$; all other $\triangle \mathrm{BIC}<-4.74$; left dlPFC: $\left.\chi^{2}(1)=2.62, p=0.11, \Delta B I C=-2.13\right)$, but a main effect of WM-load was found (PaCG: $\chi^{2}(1)=41.12, \mathrm{p}<0.001$, $\Delta \mathrm{BIC}=36.38 ;$ left dIPFC: $\chi^{2}(1)=56.35, \mathrm{p}<0.001$, $\Delta \mathrm{BIC}=51.605)($ Fig. $4 \mathrm{~A})$. Thus, high load WM-blocks (two-back) elicited more activity in the PaCG and left dlPFC than zero-back blocks, regardless of group. In the right dIPFC, we found a trend-significant interaction between group and WM-load $\left(\chi^{2}(1)=4.10, p=0.04\right.$, 
Table 1 Participant characteristics

\begin{tabular}{|c|c|c|c|c|c|c|}
\hline & & ADHD & & controls & & \\
\hline & & $\mathrm{M}(\mathrm{SD})$ & $\mathrm{N}$ & $\mathrm{M}(\mathrm{SD})$ & $\mathrm{N}$ & Statistics* \\
\hline \multicolumn{2}{|l|}{ Age (y) } & $25.18(4.06)$ & 28 & $24.40(3.86)$ & 30 & $\mathrm{t}(56)=-0.75, \mathrm{p}=0.46$ \\
\hline \multicolumn{2}{|l|}{ Education } & $4.07(1.63)$ & 28 & $4.13(1.63)$ & 30 & $\mathrm{U}=416.00, \mathrm{z}=-0.06, \mathrm{p}=0.95$ \\
\hline \multicolumn{2}{|l|}{ Medication use } & & $12 / 28$ & & & \\
\hline \multicolumn{7}{|l|}{ ADHD-RS } \\
\hline & Inattention (child) & $6.71(2.12)$ & 28 & $1.33(1.56)$ & 30 & $\mathrm{U}=815.50, \mathrm{z}=6.22, \mathrm{p}<0.001$ \\
\hline & Hyperactivity (child) & $4.57(2.74)$ & 28 & $0.47(0.78)$ & 30 & $\mathrm{U}=783.00, \mathrm{z}=5.83, \mathrm{p}<0.001$ \\
\hline & Inattention (adult) & $5.36(2.78)$ & 28 & $1.23(1.19)$ & 30 & $\mathrm{U}=764.50, \mathrm{z}=5.42, \mathrm{p}<0.001$ \\
\hline & Hyperactivity (adult) & $3.71(1.90)$ & 28 & $1.07(0.91)$ & 30 & $\mathrm{U}=752.00, \mathrm{z}=5.26, \mathrm{p}<0.001$ \\
\hline \multicolumn{7}{|l|}{$\begin{array}{l}\text { Comorbid psychiat- } \\
\text { ric disorders }\end{array}$} \\
\hline & $M D D$ & & 5 & & NA & \\
\hline \multicolumn{2}{|l|}{ STAI (trait) } & $42.19(10.81)$ & 27 & $34.10(5.27)$ & 30 & $\mathrm{U}=601.50, \mathrm{z}=3.15, \mathrm{p}=0.002$ \\
\hline \multicolumn{2}{|l|}{ STAI (state) } & $38.25(9.58)$ & 28 & $30.60(5.51)$ & 30 & $\mathrm{U}=621.00, \mathrm{z}=3.13, \mathrm{p}=0.002$ \\
\hline \multicolumn{2}{|l|}{ BDI } & $6.71(6.26)$ & 28 & $3.63(2.99)$ & 30 & $\mathrm{U}=546.00, \mathrm{z}=1.97, \mathrm{p}=0.049$ \\
\hline \multicolumn{2}{|l|}{ BIS } & $70.00(9.49)$ & 28 & $56.43(6.95)$ & 30 & $\mathrm{t}(56)=-6.24, \mathrm{p}<0.001$ \\
\hline \multicolumn{2}{|l|}{ AUDIT } & $5.82(3.74)$ & 28 & $5.97(3.36)$ & 30 & $\mathrm{U}=395.00, \mathrm{z}=-0.39, \mathrm{p}=0.67$ \\
\hline \multicolumn{2}{|l|}{ DUDIT } & $2.11(2.63)$ & 28 & $1.83(2.38)$ & 30 & $\mathrm{U}=441.50, \mathrm{z}=0.30, \mathrm{p}=0.72$ \\
\hline \multicolumn{2}{|l|}{ CUDIT } & $2.50(4.38)$ & 28 & $2.40(3.50)$ & 30 & $\mathrm{U}=378.00, \mathrm{z}=-0.72, \mathrm{p}=0.47$ \\
\hline \multicolumn{2}{|l|}{ Tobacco use } & & $11 / 28$ & & $10 / 30$ & $\chi^{2}(1, \mathrm{n}=58)=0.006, \mathrm{p}=0.94$ \\
\hline \multicolumn{2}{|l|}{ Motion (FD, mm) } & $0.15(0.07)$ & 28 & $0.12(0.03)$ & 30 & $\mathrm{U}=348.00, \mathrm{z}=-1.12, \mathrm{p}=0.26$ \\
\hline
\end{tabular}

*Normally distributed data were tested using independent samples t-tests, otherwise, Mann-Whitney tests, or $\chi^{2}$-test were used

Education (Dutch system): 1=VMBO/VMBO-T; $2=\mathrm{MBO} ; 3=\mathrm{HAVO} ; 4=\mathrm{HBO} ; 5=\mathrm{VWO} ; 6=\mathrm{WO} ; A D H D-R S$ ADHD-Rating Scale; STAI State-Trait Anxiety Inventory; BDI Beck Depression Inventory; BIS Barrat's Impulsivity Scale; AUDIT Alcohol Use Disorders Identification Test; DUDIT Drug Use Disorders Identification Test; CUDIT Cannabis Use Disorders Identification Test
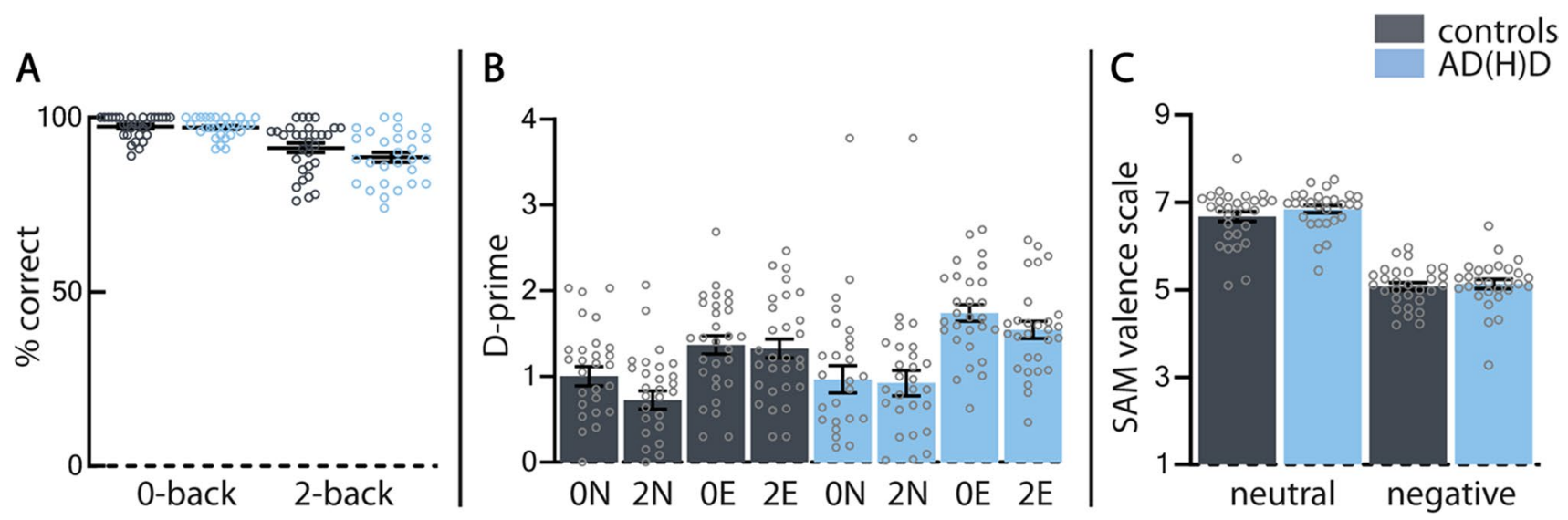

Fig. 2 Behavioral data: A) Task performance; No significant differences between participants with ADHD (blue) and controls (grey). The performance of the 2-back task was lower than the 0-back task. B) Recognition task; Neutral images were recognized less correctly

$\Delta \mathrm{BIC}=-0.65 ;$ all other $\Delta \mathrm{BIC}<-3.73)$, indicating that there was less WM-related right dlPFC activity in participants with ADHD compared to controls, which suggests that WM processes are only limitedly impaired in the investigated ADHD population. than negative images. There is a trend towards participants with ADHD recognizing negative images better than controls. C) Validation task; Both groups rated negative images as more negative than neutral images. Error bars represent the standard error

We assessed the effects of the emotional image type and group on amygdala activity during emotional processing (Fig. 4B). Model comparisons revealed evidence for a main effect of emotional images $\left(\chi^{2}(1)=37.32, p<0.001\right.$, $\triangle \mathrm{BIC}=45.65)$, showing higher amygdala activity for 
Fig. 3 Whole brain activation maps calculated with permutation tests: BOLD signal for negative vs. neutral images (top row) and the 2-back vs. 0 -back task (bottom row). Values shown are corrected and therefore correspond to the statistically significant regions. Colors correspond to 1 -p results; with red $=0.95$ (corresponding to $\mathrm{p}=0.05$ ) and yellow $=1.00$
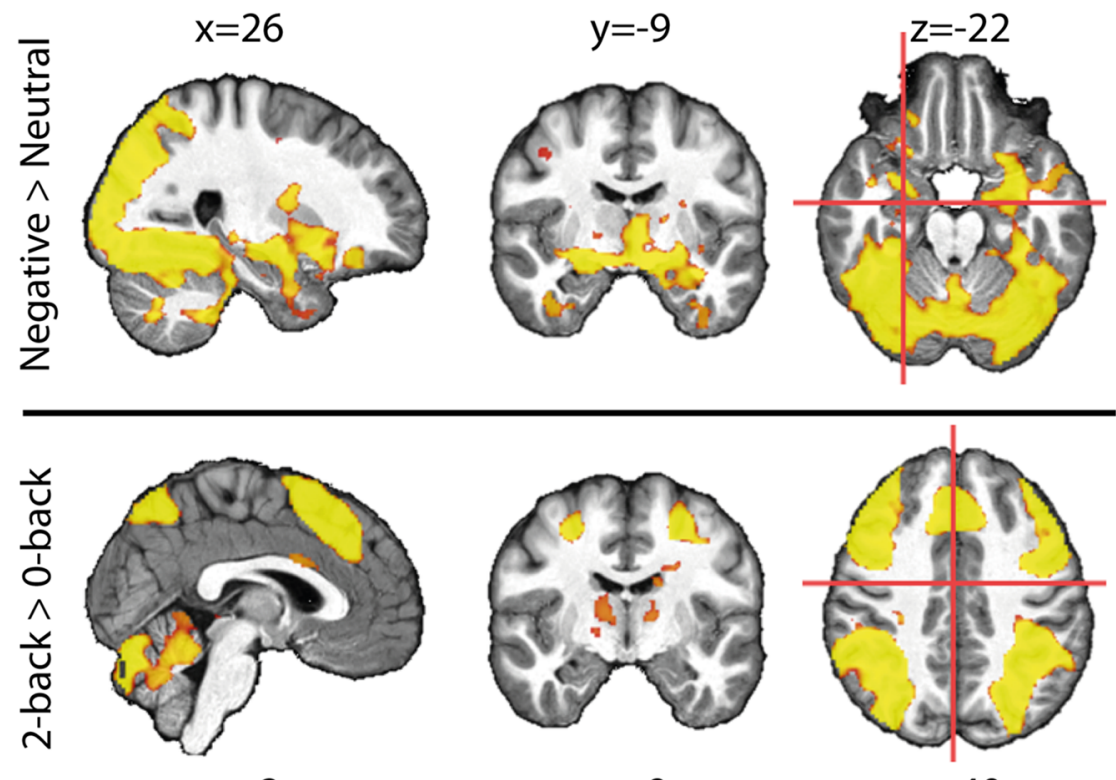

$x=2$
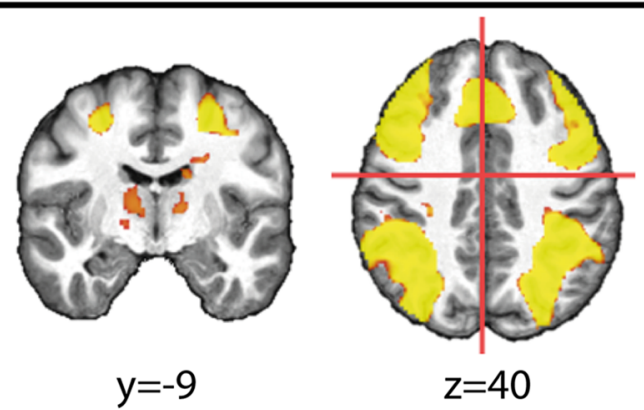

Fig. 4 Region of Interest analysis: A) Amygdala activity during negative vs. neutral images (left) and emotional images preceded by working memory blocks (right) divided into the four conditions $(0 \mathrm{~N}, 2 \mathrm{~N}, 0 \mathrm{E}$,

2E). B) PaCG activity during 2-back vs. 0-back blocks (left) and emotional images preceded by working memory blocks (right) divided into the four conditions $(0 \mathrm{~N}, 2 \mathrm{~N}, 0 \mathrm{E}, 2 \mathrm{E})$.

C) Left (left) and right (right) dlPFC activity during 2-back vs. 0-back blocks. paCG $=$ paracingulate gyrus; $\mathrm{dlPFC}=$ dorsolateral prefrontal cortex; Error bars represent the standard error
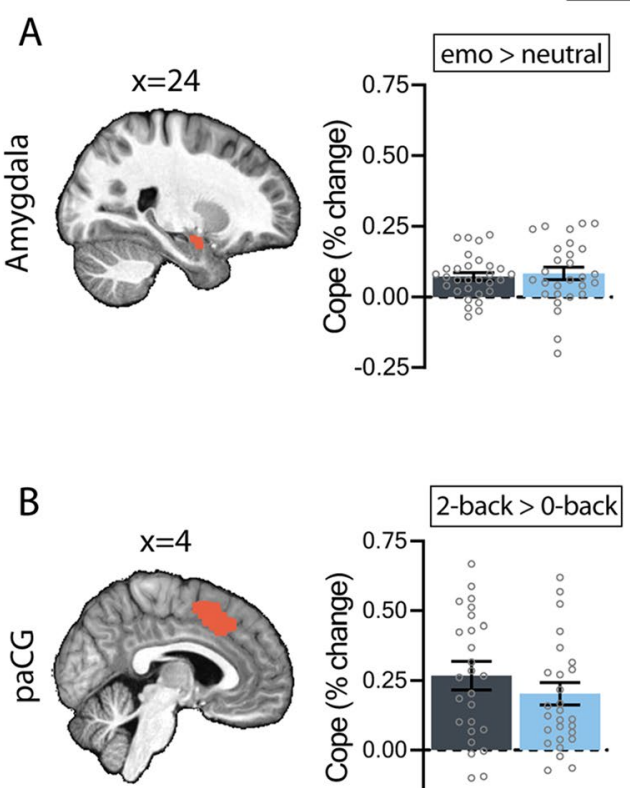

controls $\quad \mathrm{AD}(\mathrm{H}) \mathrm{D}$
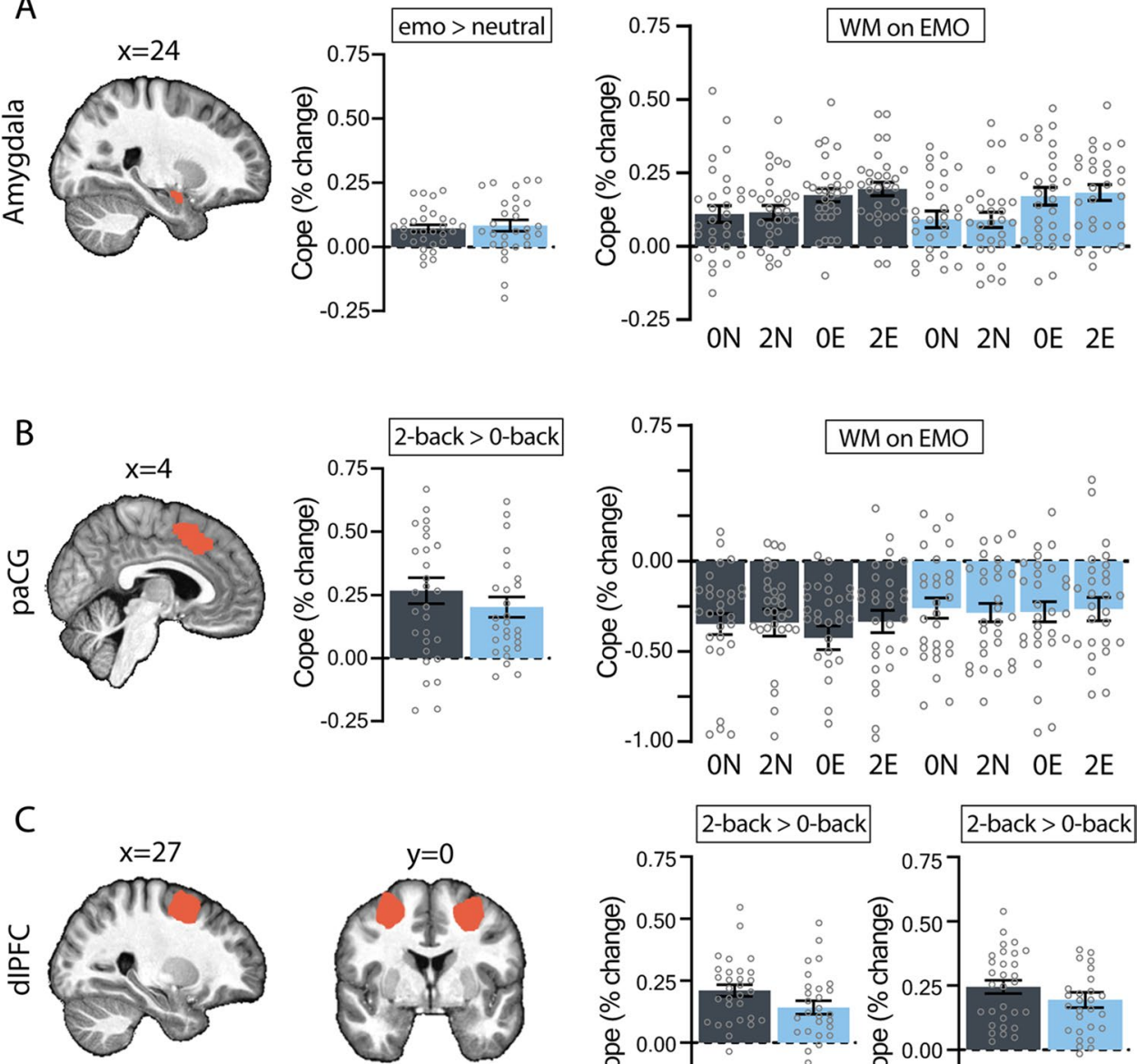
negative than neutral images, but this was not moderated by group. We furthermore found no significant three-way interactions between emotional image type, preceding WMblock, and group $\left(\chi^{2}(1)=1.40, \mathrm{p}=0.84, \Delta \mathrm{BIC}=-20.37\right.$; all other $\triangle \mathrm{BIC}<-5.19)$, which suggests that taxing $\mathrm{WM}$ did not influence ER-related amygdala activation.

Additionally, we assessed the effects of emotional images, the preceding WM-load and group on paCG activity during emotional processing, but found no three- or two-way interactions $\left(\chi^{2}(1)=3.66, p=0.45, \Delta B I C=-18.10\right.$; all other $\triangle \mathrm{BIC}<-4)$; neither did we find a main effect of emotional images $\left(\chi^{2}(1)=0.97, p=0.32, \Delta B I C=-4.47\right)$, which suggests, in contrast to our hypothesis, paCG activity did not react to emotional salient stimuli, in either the ADHD or control group.

\section{Discussion}

The primary aim of this study was to investigate whether taxing WM could ameliorate ER in adults with ADHD, and how WM and emotional reactivity (ER) would interact on a neural level. We demonstrated a significant main effect of negative emotional images on amygdala activation and a significant main effect of WM-load on activation of the paCG and dlPFC across both groups but did not find strong evidence for group differences. These findings were in line with the WM-task performance, which also did not reveal any group differences. Contrary to our hypothesis, neither amygdala nor paCG activity was reduced in response to negative vs. neutral images after inducing a high WM-load in participants with ADHD or controls.

\section{Emotional dysregulation in ADHD}

ED in ADHD consist of a complex combination of dimensions, including emotion recognition, ER, and emotional lability. In the current study, however, we did not find amygdala hyperactivity in response to negative emotional stimuli in adults with ADHD. This contrasts earlier findings of amygdala hyperactivity in response to negative emotional faces (Brotman et al., 2010; Posner, et al., 2011a, 2011b; Quinlan et al., 2017) and related to delay aversion (Lemiere et al., 2012; Van Dessel et al., 2018, 2019) in children and adolescents with ADHD and in response to loss of anticipation (Tanaka et al., 2018; Wilbertz et al., 2017) and delayed rewards (Plichta et al., 2009) in adults with ADHD. Interestingly, the only two other studies that investigated ER in adult ADHD using stimuli similar to ours (i.e., IAPS images), also failed to find differences between participants with ADHD and controls (Hägele et al., 2016; Tajima-Pozo et al., 2018). In our study, valence ratings of the IAPS images by participants with ADHD were comparable to that of controls, implying that the lack of amygdala hyperactivity was not due to the lack of experiencing the images as negative. As such, amygdala hyperactivity in participants with ADHD might be related to deficits in the processing of specific negative stimuli (e.g., loss anticipation), instead of general deficits in emotion regulation. This is in line with an earlier notion that ER, as an aspect of ED in participants with ADHD, is influenced by many factors including age and is much more complex than originally thought (Graziano \& Garcia, 2015).

\section{Working memory dysfunction in ADHD}

In line with previous literature, we found that paCG and dlPFC were activated during the WM-task (high vs. low WM-load) (Müller \& Knight, 2006; Roth \& Courtney, 2007), but we did not find group differences in WM-related left dlPFC and paCG activation or behavior. In the right dlPFC, however, we found a trend-significant interaction between group and WM-load, suggesting blunted WMrelated right dIPFC activation in participants with ADHD, which is consistent with other studies in adults (Cortese et al., 2012; Burgess et al., 2010; Ko et al., 2013), and adolescents with ADHD (Fassbender et al., 2011; Massat et al., 2012; Mattfeld et al., 2016; Prehn-Kristensen et al., 2011). In general, studies in adults with ADHD found less differences in neural recruitment between participants and controls than those in children with ADHD (Cortese et al., 2012). This suggests compensatory effects with age that has been proposed to involve parietal, occipital, and subcortical structures (i.e., cerebellum and basal ganglia) that may overcome deficits presented earlier in life (Cortese et al., 2012; Frazier et al., 2007). These compensatory mechanisms could explain why we did not find strong evidence for WM-dysfunction and associated frontal hypoactivity in adults with ADHD (Konrad \& Eickhoff, 2010; Schweitzer et al., 2000, 2004). Nevertheless, previous studies have been inconsistent in their operationalization of WM tasks (e.g., n-back, recognition), assessing multiple aspects of working memory. As a possible contributor, differences in task complexity and difficulty of different tasks may have affected the extent of activation, and may even have activated different brain regions (Müller \& Knight, 2006; Roth \& Courtney, 2007). As this makes it challenging to compare results, we suggest that future studies take the complexity of WM tasks into account by including WM tasks that place greater demand on executive components of WM.

\section{Effect of working memory activation on emotional reactivity}

Behaviorally, we found that participants recognized negative emotional images better but had worse recognition of images that were preceded by high-load WM-blocks, indicating an 
influence of WM-load on emotional memory processes. In the neuroimaging data, however, the amygdala and paCG activation were not reduced in response to negative emotional images when they were preceded by high WM-load tasks, suggesting no influence of WM-load on the neural correlates of ER. Previous studies that aimed to identify an interaction between WM and ER in controls and other patient populations used emotional interference tasks in which WM-tasks were performed during the presentation of neutral and negative emotional stimuli. Using such paradigms, high WM-load reduced amygdala activation to negative emotional stimuli in participants with an increased risk of ED (Richter et al., 2013). Also, negative emotional stimuli enhanced WM-related dIPFC activity in participants with major depressive disorder (Kerestes et al., 2012), adolescents with ADHD (Passarotti et al., 2010), and control adolescents, but not in control adults (Mueller et al., 2017). These effects were supported by impaired WM performance in presence of negative emotional stimuli in adolescents (López-Martín et al., 2013; Marx et al., 2011; Villemonteix et al., 2017) and adults with ADHD (Marx et al., 2014). Together, these studies suggest interaction effects between WM-load and ER-related amygdala (hyper-) activity. We were, however, unable to replicate these findings using a paradigm in which high WM-load was induced prior to emotional stimulation, instead of during the presentation of emotional stimuli. While our negative findings may, at least in part, be due to the limitations of our paradigm, an additional explanation is that improving ER by inducing high WM-loads will only be effective when severe impairments of ER are present. This may not always have been the case in our ADHD sample, as no group differences were found in amygdala reactivity to emotional images and only weak evidence was found for right dlPFC hypoactivity. Divergent emotional processing in ADHD has been linked to a variety of features in individuals with ADHD (Beheshti et al., 2020), such as externalizing symptoms, including conduct problems (Gillberg et al., 2004) and internalizing symptoms, such as depression and anxiety symptoms (Jarrett \& Ollendick, 2008; Sciberras et al., 2014). The participants with ADHD we included here showed relatively low scores on symptoms of anxiety and depression (although higher than the controls), which provides an indication that ER capacities may not have been strongly affected in the studied population. Indeed, other studies that found amygdala hyperactivity in individuals with ADHD also reported higher symptoms of depression and anxiety in their study populations (Maier et al., 2014; Wilbertz et al., 2013). Interestingly, recent studies demonstrated that different subtypes of ED exist and that not all individuals with ADHD experience ED in all its complexities (Hirsch et al., 2019). This thus yields the possibility that our current sample of participants with ADHD may have only relatively mild impairments in ER.
As the dimensions of ED in adult ADHD are complex and multifaceted (Beheshti et al., 2020), it is essential to develop paradigms that can disentangle the effects of executive and emotional processes in adult ADHD. Our novel fMRI-task design allows us to investigate the interactions of WM and emotional processes, like ER, which may help to understand the underlying neural mechanisms and develop novel training for ADHD.

\section{Conclusion}

We assessed possible neural correlates of the effects of targeting WM taxing on ER in adults with ADHD. We found no group differences in response to the emotional blocks on amygdala activation nor of WM-load on paCG and dIPFC activation. Although studies suggested an interaction between WM-load and emotional stimuli on the amygdala (hyper-) activity, we could not replicate these findings using our paradigm. These results might be due to compensatory effects in the adult participants with ADHD. Furthermore, targeting WM might still be effective in individuals with severe impairments in emotion regulation. These findings contribute to the understanding of the neural mechanisms of ER in controls and participants with ADHD.

Supplementary Information The online version contains supplementary material available at https://doi.org/10.1007/s11682-021-00532-6.

Acknowledgements The authors would like to thank the participants of the study for participating and Juliette Seventer and Simon Poortman for their contribution to the data collection.

Authors contributions Author contributions included conception and study design [All authors], data collection or acquisition [AK, AS], statistical analysis [AK, AS, AMK], interpretation of results [All authors], drafting the manuscript work or revising it critically for important intellectual content [All authors] and approval of final version to be published and agreement to be accountable for the integrity and accuracy of all aspects of the work [All authors].

Funding This work was supported by Amsterdam Neuroscience [to A.M.K., A.S., P.J.L., T.J.dV., and L.R.], Amsterdam Brain \& Cognition [to A.S., P.J.L., and L.R.] and Urban Mental Health Amsterdam [to P.J.L, A.S.].

Data availability The data that support the findings of this study are available from the corresponding author upon reasonable request.

Code availability The code that supports the findings of this study are available from the corresponding author upon reasonable request.

\section{Declarations}

Conflict of interest None of the authors reported biomedical financial interests or potential conflicts of interest.

Ethical approval The study was approved by the Ethics Review Board of the University of Amsterdam. 
Consent to participate Written informed consent was obtained from all participants.

Consent to publish All authors approved this version of the manuscript to be published.

Open Access This article is licensed under a Creative Commons Attribution 4.0 International License, which permits use, sharing, adaptation, distribution and reproduction in any medium or format, as long as you give appropriate credit to the original author(s) and the source, provide a link to the Creative Commons licence, and indicate if changes were made. The images or other third party material in this article are included in the article's Creative Commons licence, unless indicated otherwise in a credit line to the material. If material is not included in the article's Creative Commons licence and your intended use is not permitted by statutory regulation or exceeds the permitted use, you will need to obtain permission directly from the copyright holder. To view a copy of this licence, visit http://creativecommons.org/licenses/by/4.0/.

\section{References}

Adamson, S., \& Sellman, J. D. (2003). A prototype screening instrument for cannabis use disorder: The cannabis use disorders identification test (CUDIT) in an alcohol-dependent clinical sample. Drug and Alcohol Review, 22(3), 309-315. https://doi.org/10. 1080/0959523031000154454

American Psychiatric Association. (2000). Diagnostic and statistical manual of mental disorders (4th ed., Text Revision). Washington, DC.

Andrade, J., Pears, S., May, J., \& Kavanagh, D. J. (2012). Use of a clay modeling task to reduce chocolate craving. Appetite, 58(3), 955-963. https://doi.org/10.1016/j.appet.2012.02.044

Barkley, R. A., \& Fischer, M. (2010). The unique contribution of emotional impulsiveness to impairment in major life activities in hyperactive children as adults. Journal of the American Academy of Child and Adolescent Psychiatry, 49(5), 503-513.

Barkus, E. (2020). Effects of working memory training on emotion regulation: Transdiagnostic review. PsyCh Journal, 9(2), 258-279. https://doi.org/10.1002/pchj.353

Bates, D., Mächler, M., Bolker, B., \& Walker, S. (2014). Fitting Linear Mixed-Effects Models using lme4. arXiv, l(June), 1406.5823v. http://arxiv.org/abs/1406.5823. Accessed 16 July 2019

Beck, A. T., Ward, C., Mendelson, M., Mock, J., \& Erbaugh, J. (1961). Beck depression inventory (BDI). Archives of General Psychiatry, 4(6), 562-571.

Beheshti, A., Chavanon, M.-L., \& Christiansen, H. (2020). Emotion dysregulation in adults with attention deficit hyperactivity disorder: a meta-analysis. BMC Psychiatry. https://doi.org/10.1186/ s12888-020-2442-7

Berman, A. H., Bergman, H., Palmstierna, T., \& Schlyter, F. (2005). Evaluation of the drug use disorders identification test (DUDIT) in criminal justice and detoxification settings and in a Swedish population sample. European Addiction Research, 11, 22-31. https://doi.org/10.1159/000081413

Brotman, M. A., Rich, B. A., Guyer, A. E., Lunsford, J. R., Horsey, S. E., Reising, M. M., Thomas, L. A., Fromm, S. J., Towbin, K., Pine, D. S., \& Leibenluft, E. (2010). Amygdala activation during emotion processing of neutral faces in children with severe mood dysregulation versus ADHD or bipolar disorder. American Journal of Psychiatry, 167, 61-69.

Burgess, G. C., Depue, B. E., Ruzic, L., Willcutt, E. G., Du, Y. P., \& Banich, M. T. (2010). Attentional control activation relates to working memory in attention-deficit/hyperactivity disorder. Biological Psychiatry, 67(7), 632-640. https://doi.org/10.1016/J. BIOPSYCH.2009.10.036

Cortese, S., Kelly, C., Chabernaud, C., Proal, E., Di Martino, A., Milham, M. P., \& Xavier Castellanos, F. (2012). Toward systems neuroscience of ADHD: A meta-analysis of 55 fMRI studies. American Journal of Psychiatry, 169(10), 1038-1055.

Cousijn, J., Wiers, R. W., Ridderinkhof, K. R., van den Brink, W., Veltman, D. J., \& Goudriaan, A. E. (2014). Effect of baseline cannabis use and working-memory network function on changes in cannabis use in heavy cannabis users: A prospective fMRI study. Human Brain Mapping, 35(5), 2470-2482. https://doi.org/10. 1002/hbm.22342

Erk, S., Kleczar, A., \& Walter, H. (2007). Valence-specific regulation effects in a working memory task with emotional context. $\mathrm{Neu}$ roImage, 37(2), 623-632. https://doi.org/10.1016/j.neuroimage. 2007.05.006

Esteban, O., Ciric, R., Finc, K., Blair, R. W., Markiewicz, C. J., Moodie, C. A., Kent, J. D., Goncalves, M., DuPre, E., Gomez, D. E. P., Ye, Z., Salo, T., Valabregue, R., Amlien, I. K., Liem, F., Jacoby, N., Stojić, H., Cieslak, M., Urchs, S., ... Gorgolewski, K. J. (2020). Analysis of task-based functional MRI data preprocessed with fMRIPrep. Nature Protocols. https://doi.org/10.1038/ s41596-020-0327-3

Esteban, O., Markiewicz, C. J., Blair, R. W., Moodie, C. A., Isik, A. I., Erramuzpe, A., Kent, J. D., Goncalves, M., DuPre, E., Snyder, M., \& Oya, H. (2019). fMRIPrep: a robust preprocessing pipeline for functional MRI. Nature Methods, 16(1), 111-116. https://doi. org/10.1038/s41592-018-0235-4

Fabozzi, F. J., Focardi, S. M., Rachev, S. T., \& Arshanapalli, B. G. (2014). Appendix E: model selection criterion: AIC and BIC. The Basics of Financial Econometrics. https://doi.org/10.1002/97811 18856406.app5

Fassbender, C., Schweitzer, J. B., Cortes, C. R., Tagamets, M. A., Windsor, T. A., Reeves, G. M., \& Gullapalli, R. (2011). Working memory in attention deficit/hyperactivity disorder is characterized by a lack of specialization of brain function. PLOS ONE. https:// doi.org/10.1371/journal.pone.0027240

Frazier, T. W., Youngstrom, E. A., Glutting, J. J., \& Watkins, M. W. (2007). ADHD and achievement: Meta-analysis of the child, adolescent, and adult literatures and a concomitant study with college students. Journal of Learning Disabilities, 40(1), 49-65. https:// doi.org/10.1177/00222194070400010401

Gillberg, C., Gillberg, I. C., Rasmussen, P., Kadesjö, B., Söderström, H., Råstam, M., Johnson, M., Rothenberger, A., \& Niklasson, L. (2004). Co-existing disorders in ADHD - Implications for diagnosis and intervention. European Child and Adolescent Psychiatry, Supplement, 13(1), i80-i92. https://doi.org/10.1007/ s00787-004-1008-4

Graziano, P. A., \& Garcia, A. (2015). Attention-deficit hyperactivity disorder and children's emotion dysregulation: A meta-analysis. Clinical Psychology Review, 46, 106-123. https://doi.org/10. 1016/j.cpr.2016.04.011

Groenewold, N. A., Opmeer, E. M., de Jonge, P., Aleman, A., \& Costafreda, S. G. (2013). Emotional valence modulates brain functional abnormalities in depression: Evidence from a meta-analysis of fMRI studies. Neuroscience and Biobehavioral Reviews, 37(2), 152-163. https://doi.org/10.1016/j.neubiorev.2012.11.015

Groves, N. B., Kofler, M. J., Wells, E. L., Day, T. N., \& Chan, E. S. M. (2020). An examination of relations among working memory, ADHD symptoms, and emotion regulation. Journal of Abnormal Child Psychology, 48(4), 525-537. https://doi.org/10.1007/ s10802-019-00612-8

Hafeman, D., Bebko, G., Bertocci, M. A., Fournier, J. C., Chase, H. W., Bonar, L., et al. (2017). Amygdalaprefrontal cortical functional connectivity during implicit emotion processing differentiates 
youth with bipolar spectrum from youth with externalizing disorders. Journal of Affective Disorders, 208, 94-100. https://doi. org/10.1016/j.jad.2016.09.064

Hägele, C., Friedel, E., Schlagenhauf, F., Sterzer, P., Beck, A., Bermpohl, F., Stoy, M., Held-Poschardt, D., Wittmann, A., Ströhle, A., \& Heinz, A. (2016). Affective responses across psychiatric disorders-A dimensional approach. Neuroscience Letters, 623, 71-78. https://doi.org/10.1016/j.neulet.2016.04.037

Heatherton, T. F., Kozlowski, L. T., Frecker, R. C., \& Fagerström, K.-O. (1991). The Fagerstrom test for nicotine dependence: A revision of the Fagerstrom tolerance questionnaire. Addiction, 86(9), 1119-1127. https://doi.org/10.1111/j.1360-0443.1991. tb01879.x

Herrmann, M. J., Biehl, S. C., Jacob, C., \& Deckert, J. (2010). Neurobiological and psychophysiological correlates of emotional dysregulation in ADHD patients. ADHD Attention Deficit and Hyperactivity Disorders. https://doi.org/10.1007/s12402-010-0047-6

Hirsch, O., Chavanon, M. L., \& Christiansen, H. (2019). Emotional dysregulation subgroups in patients with adult attention-deficit/ hyperactivity disorder (ADHD): A cluster analytic approach. Scientific Reports. https://doi.org/10.1038/s41598-019-42018-y

Hulvershorn, L. A., Mennes, M., Castellanos, F. X., Di Martino, A., Milham, M. P., Hummer, T. A., \& Roy, A. K. (2014). Abnormal amygdala functional connectivity associated with emotional lability in children with attention-deficit/hyperactivity disorder. Journal of the American Academy of Child and Adolescent Psychiatry, 53(3), 351. https://doi.org/10.1016/j.jaac.2013.11.012

Hung, Y., Gaillard, S. L., Yarmak, P., \& Arsalidou, M. (2018). Dissociations of cognitive inhibition, response inhibition, and emotional interference: Voxelwise ALE meta-analyses of fMRI studies. Human Brain Mapping, 39(10), 4065-4082. https://doi. org/10.1002/hbm. 24232

Jarrett, M. A., \& Ollendick, T. H. (2008). A conceptual review of the comorbidity of attention-deficit/hyperactivity disorder and anxiety: Implications for future research and practice. Clinical Psychology Review, 28(7), 1266-1280. https://doi.org/10. 1016/j.cpr.2008.05.004

Jenkinson, M., Beckmann, C. F., Behrens, T. E. J., Woolrich, M. W., \& Smith, S. M. (2012). FSL. NeuroImage, 62, 782-790. https:// doi.org/10.1016/j.neuroimage.2011.09.015

Kaag, A. M., Goudriaan, A. E., De Vries, T. J., Pattij, T., \& Wiers, R. W. (2018). A high working memory load prior to memory retrieval reduces craving in non-treatment seeking problem drinkers. Psychopharmacology (berl), 235(3), 695-708. https://doi.org/ 10.1007/s00213-017-4785-4

Kerestes, R., Ladouceur, C. D., Meda, S., Nathan, P. J., Blumberg, H. P., Maloney, K., Ruf, B., Saricicek, A., Pearlson, G. D., Bhagwagar, Z., \& Phillips, M. L. (2012). Abnormal prefrontal activity subserving attentional control of emotion in remitted depressed patients during a working memory task with emotional distracters. Psychological Medicine, 42(1), 29-40. https://doi.org/10.1017/ S0033291711001097

Ko, C. H., Yen, J. Y., Yen, C. F., Chen, C. S., Lin, W. C., Wang, P. W., \& Liu, G. C. (2013). Brain activation deficit in increased-load working memory tasks among adults with ADHD using fMRI. European Archives of Psychiatry and Clinical Neuroscience, 263(7), 561-573. https://doi.org/10.1007/s00406-013-0407-2

Konrad, K., \& Eickhoff, S. B. (2010). Is the ADHD brain wired differently? A review on structural and functional connectivity in attention deficit hyperactivity disorder. Human Brain Mapping, 31(6), 904-916. https://doi.org/10.1002/hbm.21058

Kooij, S. J. J., Boonstra, A. M., Swinkels, S. H. N., Bekker, E. M., de Noord, I., \& Buitelaar, J. K. (2008). Reliability, validity, and utility of instruments for self-report and informant report concerning symptoms of ADHD in adult patients. Journal of Attention Disorders, 11(4), 445-458. https://doi.org/10.1177/1087054707299367
Lang, P. J., Bradley, M. M., \& Cuthbert, B. N. (2005). International Affective Picture System (IAPS): Affective ratings of UNPROOFED PAGES 46 Emotion Elicitation pictures and instruction manual. Technical Report no.A-6.University of Florida, Gainesville, Fl.

Lang, P. (1980). Behavioral treatment and bio-behavioral assessment: Computer applications. Technology in mental health care delivery systems (pp. 119-137). Ablex.

Lemiere, J., Danckaerts, M., Van Hecke, W., Mehta, M. A., Peeters, R., Sunaert, S., \& Sonuga-Barke, E. (2012). Brain activation to cues predicting inescapable delay in adolescent attention deficit/ hyperactivity disorder: An fMRI pilot study. Brain Research, 1450, 57-66. https://doi.org/10.1016/j.brainres.2012.02.027

Lenzi, F., Cortese, S., Harris, J., \& Masi, G. (2018). Pharmacotherapy of emotional dysregulation in adults with ADHD: A systematic review and meta-analysis. Neuroscience and Biobehavioral Reviews. https://doi.org/10.1016/j.neubiorev.2017.08.010

Lin, T., Vaisvaser, S., Fruchter, E., Admon, R., Wald, I., Pine, D. S., Bar-Haim, Y., \& Hendler, T. (2015). A neurobehavioral account for individual differences in resilience to chronic military stress. Psychological Medicine, 45, 1011-1023. https://doi.org/10. 1017/S0033291714002013

López-Martín, S., Albert, J., Fernández-Jaén, A., \& Carretié, L. (2013). Emotional distraction in boys with ADHD: Neural and behavioral correlates. Brain and Cognition, 83(1), 10-20. https://doi.org/10.1016/j.bandc.2013.06.004

Maier, S. J., Szalkowski, A., Kamphausen, S., Feige, B., Perlov, E., Kalisch, R., Jacob, G. A., Philipsen, A., Tüscher, O., \& van Elst, L. T. (2014). Altered cingulate and amygdala response towards threat and safe cues in attention deficit hyperactivity disorder. Psychological Medicine, 44(1), 85-98. https://doi.org/10.1017/ S0033291713000469

Markus, W., De Weert-Van Oene, G. H., Woud, M. L., Becker, E. S., \& Dejong, C. A. J. (2016). Are addiction-related memories malleable by working memory competition? Transient effects on memory vividness and nicotine craving in a randomized lab experiment. Journal of Behavior Therapy and Experimental Psychiatry, 52, 83-91. https://doi.org/10.1016/j.jbtep.2016.03.007

Marteau, T. M., \& Bekker, H. (1992). The development of a six-item short-form of the state scale of the Spielberger State-Trait Anxiety Inventory (STAI). British Journal of Clinical Psychology, 31(3), 301-306. https://doi.org/10.1111/j.2044-8260.1992.tb00997.x

Marx, I., Domes, G., Havenstein, C., Berger, C., Schulze, L., \& Herpertz, S. C. (2011). Enhanced emotional interference on working memory performance in adults with ADHD. The World Journal of Biological Psychiatry, 12, 70-75. https://doi.org/10.3109/15622 975.2011.599213

Marx, I., Krause, J., Berger, C., \& Häßler, F. (2014). Dissociable patterns in the control of emotional interference in adults with attention-deficit/hyperactivity disorder (ADHD) and in adults with alcohol dependence. PLoS ONE. https://doi.org/10.1371/journal. pone. 0107750

Massat, I., Slama, H., Kavec, M., Linotte, S., Mary, A., Baleriaux, D., Metens, T., Mendlewicz, J., \& Peigneux, P. (2012). Working memory-related functional brain patterns in never medicated children with ADHD. PLOS ONE. https://doi.org/10.1371/journ al.pone.004939

Materna, L., Wiesner, C. D., Shushakova, A., Trieloff, J., Weber, N., Engell, A., Schubotz, R. I., Bauer, J., Pedersen, A., \& Ohrmann, P. (2019). Adult patients with ADHD differ from healthy controls in implicit, but not explicit, emotion regulation. Journal of Psychiatry and Neuroscience. https://doi.org/10.1503/jpn.180139

Mattfeld, A. T., Whitfield-Gabrieli, S., Biederman, J., Spencer, T., Brown, A., Fried, R., \& Gabrieli, J. D. E. (2016). Dissociation of working memory impairments and attention-deficit/hyperactivity 
disorder in the brain. NeuroImage: Clinical, 10, 274-282. https:// doi.org/10.1016/j.nicl.2015.12.003

May, J., Andrade, J., Panabokke, N., \& Kavanagh, D. (2010). Visuospatial tasks suppress craving for cigarettes. Behaviour Research and Therapy, 48(6), 476-485. https://doi.org/10.1016/j.brat.2010. 02.001

McClelland, A., Kemps, E., \& Tiggeman, M. (2006). Reduction of vividness and associated craving in personalized food imagery. Journal of Clinical Psychology, 62(3), 355-365. https://doi.org/ 10.1002/jclp

Miró-Padilla, A., Bueichekú, E., Ventura-Campos, N., Flores-Compañ, M.-J., Parcet, M. A., \& Ávila, C. (2018). Long-term brain effects of N-back training: An fMRI study. Brain Imaging and Behavior. https://doi.org/10.1007/s11682-018-9925-x

Mueller, S. C., Cromheeke, S., Siugzdaite, R., \& Nicolas Boehler, C. (2017). Evidence for the triadic model of adolescent brain development: Cognitive load and task-relevance of emotion differentially affect adolescents and adults. Developmental Cognitive Neuroscience, 26, 91-100. https://doi.org/10.1016/j.den.2017.06.004

Müller, N. G., \& Knight, R. T. (2006). The functional neuroanatomy of working memory: Contributions of human brain lesion studies. Neuroscience, 139(1), 51-58. https://doi.org/10.1016/j.neuroscien ce.2005.09.018

Passarotti, A. M., Sweeney, J. A., \& Pavuluri, M. N. (2010). Emotion processing influences working memory circuits in pediatric bipolar disorder and attention-deficit/hyperactivity disorder. Journal of the American Academy of Child and Adolescent Psychiatry, 49(10), 1064-1080. https://doi.org/10.1016/j.jaac.2010.07.009

Patton, J. H., Stanford, M. S., \& Barratt, E. S. (1995). Factor structure of the Barratt impulsiveness scale. Journal of Clinical Psychology, 51(6), 768-774.

Plichta, M. M., Vasic, N., Wolf, R. C., Lesch, K. P., Brummer, D., Jacob, C., Fallgatter, A. J., \& Grön, G. (2009). Neural hyporesponsiveness and hyperresponsiveness during immediate and delayed reward processing in adult attention-deficit/hyperactivity disorder. Biological Psychiatry, 65(1), 7-14. https://doi.org/10.1016/j.biops ych.2008.07.008

Posner, J., Maia, T. V., Fair, D., Peterson, B. S., Sonuga-Barke, E. J., \& Nagel, B. J. (2011). The attenuation of dysfunctional emotional processing with stimulant medication: An fMRI study of adolescents with ADHD. Psychiatry Research-Neuroimaging, 193(3), 151-160. https://doi.org/10.1016/j.pscychresns.2011.02.005

Posner, J., Nagel, B. J., Maia, T. V., Mechling, A., Oh, M., Wang, Z., \& Peterson, B. S. (2011). Abnormal amygdalar activation and connectivity in adolescents with attention-deficit/hyperactivity disorder. Journal of the American Academy of Child and Adolescent Psychiatry, 50(8), 1-19. https://doi.org/10.1016/j.jaac. 2011.05.010

Prehn-Kristensen, A., Krauel, K., Hinrichs, H., Fischer, J., Malecki, U., Schuetze, H., Wolff, S., Jansen, O., Duezel, E., \& Baving, L. (2011). Methylphenidate does not improve interference control during a working memory task in young patients with attentiondeficit hyperactivity disorder. Brain Research, 1388, 56-68. https://doi.org/10.1016/j.brainres.2011.02.07

Quinlan, E. B., Cattrell, A., Jia, T., Artiges, E., Banaschewski, T., Barker, G., Bokde, A. L. W., Bromberg, U., Büchel, C., Brühl, R., Conrod, P. J., Desrivieres, S., Flor, H., Frouin, V., Gallinat, J., Garavan, H., Gowland, P., Heinz, A., Martinot, J. L., ... IMAGEN Consortium. (2017). Psychosocial stress and brain function in adolescent psychopathology. American Journal of Psychiatry, 174(8), 785-794. https://doi.org/10.1176/appi.ajp.2017.1604046

R Development Core Team, R. F. F. S. C. (2011). R: A language and environment for statistical computing.

Richter, S., Gorny, X., Machts, J., Behnisch, G., Wüstenberg, T., Herbort, M. C., Münte, T. F., Seidenbecher, C. I., \& Schott, B. H. (2013). Effects of AKAP5 Pro100Leu genotype on working memory for emotional stimuli. PLoS ONE. https://doi.org/10. 1371/journal.pone.0055613

Roth, J. K., \& Courtney, S. M. (2007). Neural system for updating object working memory from different sources: Sensory stimuli or long-term memory. NeuroImage, 38(3), 617-630. https://doi. org/10.1016/j.neuroimage.2007.06.037

Saunders, J. B., Aasland, O. G., Babor, T. F., De la Fuente, J. R., \& Grant, M. (1993). Development of the alcohol use disorders identification test (AUDIT): WHO collaborative project on early detection of persons with harmful alcohol consumption-II. Addiction, 88(6), 791-804. https://doi.org/10.1111/j.1360-0443.1993. tb02093.x

Schwarz, G. (1978). Estimating the dimension of a model. The Annals of Statistics. https://doi.org/10.1214/aos/1176344136

Schweitzer, J. B., Faber, T. L., Grafton, S. T., Tune, L. E., Hoffman, J. M., \& Kilts, C. D. (2000). Alterations in the functional anatomy of working memory in adult attention deficit hyperactivity disorder. American Journal of Psychiatry, 157(2), 278-280. https://doi.org/ 10.1176/appi.ajp.157.2.278

Schweitzer, J. B., Lee, D. O., Hanford, R. B., Zink, C. F., Ely, T. D., Tagamets, M. A., Hoffman, J. M., Grafton, S. T., \& Kilts, C. D. (2004). Effect of methylphenidate on executive functioning in adults with attention-deficit/hyperactivity disorder: Normalization of behavior but not related brain activity. Biological Psychiatry, 56(8), 597-606. https://doi.org/10.1016/j.biopsych. 2004.07.011

Schweizer, S., Grahn, J., Hampshire, A., Mobbs, D., \& Dalgleish, T. (2013). Training the emotional brain: Improving affective control through emotional working memory training. Journal of Neuroscience, 33(12), 5301-5311. https://doi.org/10.1523/ JNEUROSCI.2593-12.2013

Sciberras, E., Lycett, K., Efron, D., Mensah, F., Gerner, B., \& Hiscock, H. (2014). Anxiety in children with attention-deficit/ hyperactivity disorder. Pediatrics, 133(5), 801-808. https://doi.org/10.1542/ peds.2013-3686

Sergerie, K., Chochol, C., \& Armony, J. L. (2008). The role of the amygdala in emotional processing: A quantitative meta-analysis of functional neuroimaging studies. Neuroscience \& Biobehavioral Reviews, 32(4), 811-830. https://doi.org/10.1016/J.NEUBI OREV.2007.12.002

Shackman, A. J., Salomons, T. V., Slagter, H. A., Fox, A. S., Winter, J. J., \& Davidson, R. J. (2011). The integration of negative affect, pain and cognitive control in the cingulate cortex. Nature Reviews Neuroscience. https://doi.org/10.1038/nrn2994

Song, S., Zilverstand, A., Song, H., D'Oleire Uquillas, F., Wang, Y., Xie, C., Cheng, L., \& Zou, Z. (2017). The influence of emotional interference on cognitive control: A meta-analysis of neuroimaging studies using the emotional Stroop task. Scientific Reports, 7(1), 1-9. https://doi.org/10.1038/s41598-017-02266-2

Tajima-Pozo, K., Ruiz-Manrique, G., Yus, M., Arrazola, J., \& Montañes-Rada, F. (2015). Correlation between amygdala volume and impulsivity in adults with attention-deficit hyperactivity disorder. Acta Neuropsychiatrica, 27(6), 362-367. https://doi.org/10.1017/ neu.2015.34

Tajima-Pozo, K., Yus, M., Ruiz-Manrique, G., Lewczuk, A., Arrazola, J., \& Montañes-Rada, F. (2018). Amygdala abnormalities in adults with ADHD. Journal of Attention Disorders, 22(7), 671-678. https://doi.org/10.1177/1087054716629213

Tanaka, S. C., Yahata, N., Todokoro, A., Kawakubo, Y., Kano, Y., Nishimura, Y., Ishii-Takahashi, A., Ohtake, F., \& Kasai, K. (2018). Preliminary evidence of altered neural response during intertemporal choice of losses in adult attention-deficit hyperactivity disorder. Scientific Reports, 8(1), 1-7. https://doi.org/10.1038/ s41598-018-24944-5

Tsai, C. J., Lin, H. Y., Tseng, I. W. Y., \& Gau, S. S. F. (2020). Brain voxel-based morphometry correlates of emotion dysregulation in 
attention-deficit hyperactivity disorder. Brain Imaging and Behavior. https://doi.org/10.1007/s11682-020-00338-y

van den Hout, M. A., Eidhof, M. B., Verboom, J., Littel, M., \& Engelhard, I. M. (2014). Blurring of emotional and non-emotional memories by taxing working memory during recall. Cognition and Emotion, 28(4), 717-727. https://doi.org/10.1080/02699931. 2013.848785

Van Dessel, J., Sonuga-Barke, E., Mies, G., Lemiere, J., Van der Oord, S., Morsink, S., \& Danckaerts, M. (2018). Delay aversion in attention deficit/hyperactivity disorder is mediated by amygdala and prefrontal cortex hyper-activation. Journal of Child Psychology and Psychiatry and Allied Disciplines, 59(8), 888-899. https:// doi.org/10.1111/jcpp. 12868

Van Dessel, J., Sonuga-Barke, E., Moerkerke, M., Van der Oord, S., Lemiere, J., Morsink, S., \& Danckaerts, M. (2019). The amygdala in adolescents with attention-deficit/hyperactivity disorder: Structural and functional correlates of delay aversion. World Journal of Biological Psychiatry. https://doi.org/10.1080/15622975.2019. 1585946

Van Dillen, L. F., Heslenfeld, D. J., \& Koole, S. L. (2009). Tuning down the emotional brain: An fMRI study of the effects of cognitive load on the processing of affective images. NeuroImage, 45(4), 1212-1219. https://doi.org/10.1016/j.neuroimage.2009. 01.016

Villemonteix, T., Marx, I., Septier, M., Berger, C., Hacker, T., Bahadori, S., Acquaviva, E., \& Massat, I. (2017). Attentional control of emotional interference in children with ADHD and typically developing children: An emotional N-back study. Psychiatry Research, 254, 1-7. https://doi.org/10.1016/j.psychres. 2017.04.027

Wehmeier, P. M., Schacht, A., \& Barkley, R. A. (2010). Social and emotional impairment in children and adolescents with ADHD and the impact on quality of life. The Journal of Adolescent Health, 46(3), 209-217.

Wilbertz, G., Trueg, A., Sonuga-Barke, E. J. S., Blechert, J., Philipsen, A., \& van Elst, L. T. (2013). Neural and psychophysiological markers of delay aversion in attention-deficit hyperactivity disorder. Journal of Abnormal Psychology, 122(2), 566-572. https:// doi.org/10.1037/a0031924

Wilbertz, G., Delgado, M. R., Tebartz Van Elst, L., Maier, S., Philipsen, A., \& Blechert, J. (2017). Neural response during anticipation of monetary loss is elevated in adult attention deficit hyperactivity disorder. World Journal of Biological Psychiatry, 18(4), 268-278. https://doi.org/10.3109/15622975.2015.1112032

Winkler, A. M., Ridgway, G. R., Webster, M. A., Smith, S. M., \& Nichols, T. E. (2014). Permutation inference for the general linear model. NeuroImage, 92, 381-397. https://doi.org/10.1016/J. NEUROIMAGE.2014.01.060

Publisher's Note Springer Nature remains neutral with regard to jurisdictional claims in published maps and institutional affiliations. 